Third Place, Graduate division, MPD SME Student Poster Contest 2014

\title{
Increasing the preheat strength of cornstarch-bonded pellets
}

\author{
Joseph A. Halt \\ Michigan Technological University, Houghton, MI \\ Email: jahalt@mtu.edu
}

\section{Introduction}

The recent boom in natural gas production and lower natural gas prices in the United States have resulted in increased interest in direct reduction iron making technologies. These processes have typically used purer iron ore concentrate pellets as feedstock compared to the blast furnace process. One way to increase pellet purity is to use an organic binder, such as cornstarch, instead of the traditional binder, bentonite clay. Bentonite contains mainly montmorillonite, an aluminosilicate mineral, so it increases pellet $\mathrm{SiO}_{2}$ and $\mathrm{Al}_{2} \mathrm{O}_{3}$ contents when used as a binder. However, pellets made with cornstarch binders have significantly lower preheat strengths than bentonite-bonded pellets. Thus, the aim of this investigation was to increase the preheat strengths of cornstarch-bonded pellets.

\section{Methods and results}

Iron ore concentrate, binder and additives were mixed and agglomerated following standard procedures. All binders/additives used in these tests were dry powders, as that is the form desired by most pellet plant operators. Additives were dosed at $0.5-2 \mathrm{lb} / \mathrm{lt}$ [convert]. After drying, pellets were preheated at $1,100^{\circ} \mathrm{C}\left(2,012^{\circ} \mathrm{F}\right)$ for $30 \mathrm{~min}$. After cooling, the pellets were crushed in a compression tester $(2.5 \mathrm{~cm} / \mathrm{min}$ or $0.98 \mathrm{in./}$ min). The compression strengths are shown in Fig. 1: error bars represent the $95 \%$ confidence intervals of twenty pellets for each condition.

As expected, pellets made using a typical dose of bentonite binder had significantly higher preheat strength than pellets made using cornstarch binder (Fig. 1 left). Using cornstarch plus additives commonly used at many iron ore concentration and pelletization plants, a significant portion of the preheat strength could be regained (Fig. 1 right). Glass-H was the most effective additive. At a $0.5 \mathrm{lb} / \mathrm{lt}$ [convert] dose of Glass-H, the preheat pellet strengths were thirteen percent lower than when using bentonite binder. Based on trends not shown here, the optimal Glass-H dose appeared to be lower than $0.5 \mathrm{lb} / \mathrm{lt}$ [convert].

\section{Conclusion}

The preheat strength of cornstarch-bonded pellets was significantly increased using the dispersant Glass-H. For enhanced preheat strengths, the optimal Glass-H dose appears to be lower than $0.5 \mathrm{lb} / \mathrm{lt}$. Future work will be conducted in order to determine the fundamental mechanisms behind the increase in strength.
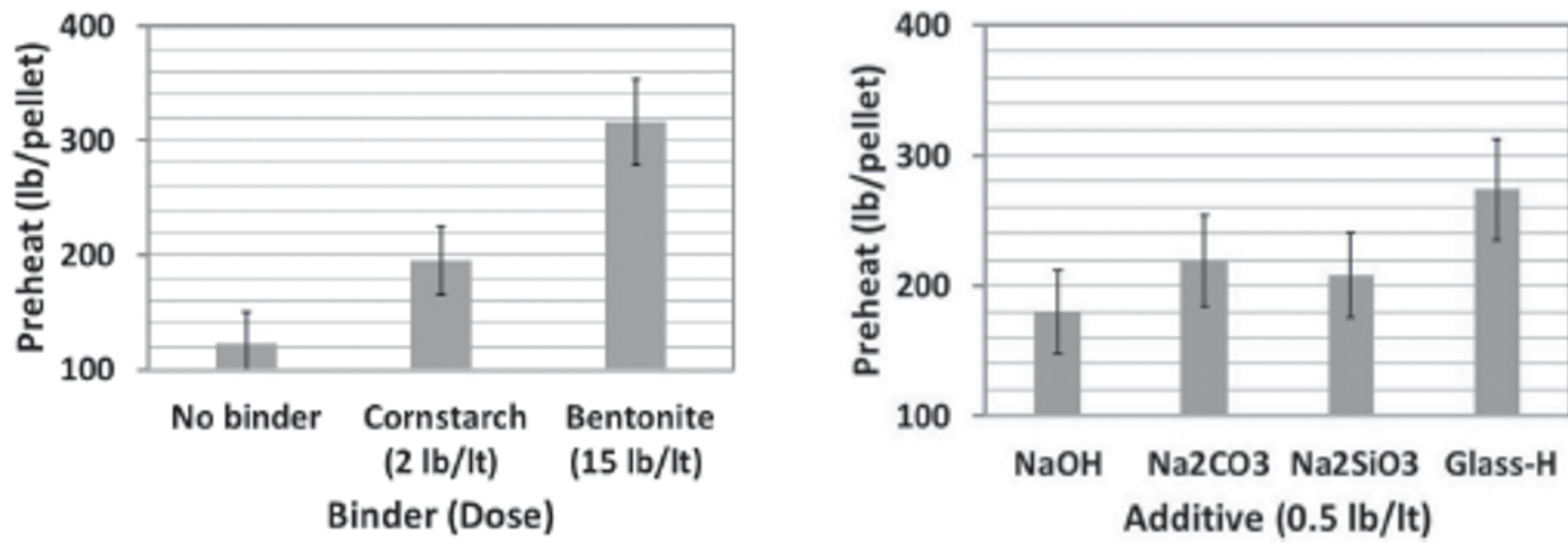

Figure 1 - Effect of binders (left) and additives (right) on the strength of preheated pellets. Pellets were preheated at $1,100^{\circ}$ $\mathrm{C}\left(2012^{\circ} \mathrm{F}\right)$ for $30 \mathrm{~min}$. Additives were tested in pellets made with a pregelled cornstarch at a dose of $2 \mathrm{lb} / \mathrm{lt}$ [convert]. 